Article

\title{
Combined X-ray and Raman Studies on the Effect of Cobalt Additives on the Decomposition of Magnesium Borohydride
}

\section{Olena Zavorotynska ${ }^{1}$, Stefano Deledda ${ }^{1}$, Jenny G. Vitillo ${ }^{2,3}$, Ivan Saldan ${ }^{1,4}$, Matylda N. Guzik ${ }^{1}$, Marcello Baricco ${ }^{2}$, John C. Walmsley ${ }^{5}$, Jiri Muller ${ }^{1}$ and Bjørn C. Hauback ${ }^{1, *}$}

1 Physics Department, Institute for Energy Technology, P.O. Box 40, Kjeller NO-2027, Norway; E-Mails: olenaz@ife.no (O.Z.); stefano.deledda@ife.no (S.D.); saldanivan@gmail.com (I.S.); mnguzik@gmail.com (M.N.G.); jiri.muller@ife.no (J.M.)

2 Department of Chemistry, Centre for Nanostructured Interfaces and Surfaces (NIS), National Interuniversity Consortium of Materials Science and Technology (INSTM), University of Turin, Via P. Giuria 7, Turin 10125, Italy; E-Mails: jenny.vitillo@unito.it or jenny.vitillo@uninsubria.it (J.G.V.); marcello.baricco@unito.it (M.B.)

3 Science and Technology Department, University of Insubria, Via Valleggio 11, Como 22100, Italy

4 Department of Physical and Colloid Chemistry, I.F. National University of Lviv, 6 Kyryla and Mefodia Str., Lviv UA-79005, Ukraine

5 SINTEF Materials \& Chemistry, Trondheim NO-7465, Norway; E-Mail: john.walmsley@sintef.no

* Author to whom correspondence should be addressed; E-Mail: bjorn.hauback@ife.no; Tel.: +47-974-088-44; Fax: +47-638-109-20.

Academic Editor: Craig M. Jensen

Received: 24 July 2015 / Accepted: 19 August 2015 / Published: 27 August 2015

\begin{abstract}
Magnesium borohydride $\left(\mathrm{Mg}\left(\mathrm{BH}_{4}\right)_{2}\right)$ is one of the most promising hydrogen storage materials. Its kinetics of hydrogen desorption, reversibility, and complex reaction pathways during decomposition and rehydrogenation, however, present a challenge, which has been often addressed by using transition metal compounds as additives. In this work the decomposition of $\mathrm{Mg}\left(\mathrm{BH}_{4}\right)_{2}$ ball-milled with $\mathrm{CoCl}_{2}$ and $\mathrm{CoF}_{2}$ additives, was studied by means of a combination of several in-situ techniques. Synchrotron X-ray diffraction and Raman spectroscopy were used to follow the phase transitions and decomposition of $\mathrm{Mg}\left(\mathrm{BH}_{4}\right)_{2}$. By comparison with pure milled $\mathrm{Mg}\left(\mathrm{BH}_{4}\right)_{2}$, the temperature for the $\gamma \rightarrow \varepsilon$ phase transition in the samples with $\mathrm{CoF}_{2}$ or $\mathrm{CoCl}_{2}$ additives was reduced by $10-45{ }^{\circ} \mathrm{C}$. In-situ Raman measurements showed the formation of a decomposition phase with vibrations at
\end{abstract}


2513, 2411 and $766 \mathrm{~cm}^{-1}$ in the sample with $\mathrm{CoF}_{2}$. Simultaneous X-ray absorption measurements at the Co K-edge revealed that the additives chemically transformed to other species. $\mathrm{CoF}_{2}$ slowly reacted upon heating till $\sim 290{ }^{\circ} \mathrm{C}$, whereas $\mathrm{CoCl}_{2}$ transformed drastically at $\sim 180^{\circ} \mathrm{C}$.

Keywords: cobalt additives; hydrogen storage; in-situ; magnesium borohydride $\left(\mathrm{Mg}\left(\mathrm{BH}_{4}\right)_{2}\right)$; X-ray absorption spectroscopy (XAS); synchrotron X-ray diffraction

\section{Introduction}

Metal borohydrides (or tetrahydroborates) are complex hydrides containing $\mathrm{BH}_{4}^{-}$anions counterbalanced by metal cations. Group I and II borohydrides (except Be) have pure ionic interactions between the cations and $\mathrm{BH}_{4}{ }^{-}$and thus strong $\mathrm{B}-\mathrm{H}$ bonding, which renders the compounds particularly stable, decomposing only above $200{ }^{\circ} \mathrm{C}$ with typically pure $\mathrm{H}_{2}$ release [1,2]. In transition metal (TM) or mixed cation borohydrides, on the contrary, the interaction between the cation(s) and $\mathrm{H}^{-}$of the $\mathrm{BH}_{4}^{-}$ group can be partially covalent, which significantly destabilizes the B-H bonding and promotes decomposition even below room temperature (RT), but with release of mostly $\mathrm{B}_{2} \mathrm{H}_{6}$ [3-8]. TM borohydrides can, in many cases, be obtained by reaction of the corresponding chloride with an alkali borohydride $[5,8]$. Due to their exceptionally high gravimetric hydrogen content (up to $18 \mathrm{wt} \%$ in $\mathrm{LiBH}_{4}$ ), metal borohydrides, both stable and unstable, have been extensively studied for hydrogen storage applications $[2,9,10]$.

Magnesium borohydride $\left(\mathrm{Mg}\left(\mathrm{BH}_{4}\right)_{2}\right)$ has one of the highest hydrogen densities (14.5 wt.\% and $>100 \mathrm{~kg} \cdot \mathrm{m}^{-3}$ ) [11-14]. DFT calculations have predicted its decomposition to a mixture of $\mathrm{MgB}_{x}$ (or $\mathrm{MgB}_{12} \mathrm{H}_{12}$ ) with $\mathrm{MgH}_{2}$ below $100^{\circ} \mathrm{C}$, accompanied by $\mathrm{H}_{2}$ release [15-18]. Experimentally $\mathrm{Mg}\left(\mathrm{BH}_{4}\right)_{2}$ decomposes only at $\sim 200{ }^{\circ} \mathrm{C}$, which is still a low temperature compared to other stable borohydrides. The decomposition is a multi-step reaction, the path depending on the experimental conditions, and involves the formation of amorphous boron hydride compounds at $285{ }^{\circ} \mathrm{C}-320^{\circ} \mathrm{C}$ [19-27]. Nevertheless, it has been shown that $\mathrm{H} \rightarrow \mathrm{D}$ substitution at the surface occurs at $\sim 100{ }^{\circ} \mathrm{C}$ in $\gamma-\mathrm{Mg}\left(\mathrm{BH}_{4}\right)_{2}$ [28], which is a much lower temperature than seen in other ionic borohydrides [29-31], confirming a comparatively low stability of the B-H bonds in the compound. These inconsistencies between the theoretical stability of $\mathrm{Mg}\left(\mathrm{BH}_{4}\right)_{2}$ and experimental $T_{\text {dec }}$ can be explained by kinetic barriers, such as $\mathrm{H}$ diffusion in the bulk [28], and/or the formation of intermediate phases disregarded in the calculations [32].

Addition of TM-based additives, e.g., oxides, halides, metal nanoparticles, has been one of the strategies used to enhance the hydrogen storage performance of borohydrides. After the report of Bogdanovic et al. [33] that Ti-based additives resulted in significantly improved hydrogen cycling properties of $\mathrm{NaAlH}_{4}$, this approach has been applied to a wide range of similar compounds and composites, including metal borohydrides [2,26,34-42]. The addition of several TM-compounds has indeed resulted in improved hydrogen storage properties of stable borohydrides and related composites, including decrease in $T_{\mathrm{dec}}$ [35,41], in some cases remarkably by as much as $200{ }^{\circ} \mathrm{C}$ [36]. Enhancement of the desorption and absorption reactions kinetics [26,42], improved hydrogen purity, reversibility [37] and borohydride synthesis from the decomposition products [39] has also been documented. 
A few studies have addressed the mechanisms of the additives' "catalytic" activity [26,34,42,43]. It has been shown that the additives undergo chemical transformations and form alkali- or alkaline-earth metal halides [34], finely dispersed metal clusters or/and boride-like structures $[26,42,43]$. The latter can be stable upon cycling [26,42] or change the metal-B coordination numbers reversibly [43].

In our previous works [26,42] we have shown that $\mathrm{Ni}$ - and Co-based additives have an effect on the kinetics of hydrogen desorption and absorption in $\gamma-\mathrm{Mg}\left(\mathrm{BH}_{4}\right)_{2}$ [13]. Ex-situ X-ray absorption spectroscopy (XAS) studies have shown that the additives were chemically modified to compounds similar to Ni- and Co-borides after first decomposition of $\mathrm{Mg}\left(\mathrm{BH}_{4}\right)_{2}$. In this work we present a series of in-situ measurements involving quasi simultaneous monitoring of the changes in both the Co-additives and in $\gamma-\mathrm{Mg}\left(\mathrm{BH}_{4}\right)_{2}$. XAS spectroscopy was applied to follow the modifications in the additives, and synchrotron radiation powder X-ray diffraction (SR-PXD) with Raman spectroscopy were used to contemporaneously characterize the borohydride matrix. Additional characterization of the samples was performed by transmission electron microscopy (TEM) ex situ.

\section{Results}

\subsection{Synchrotron Radiation Powder X-ray Diffraction (SR-PXD) Study of $M g\left(B H_{4}\right)_{2}$ Decomposition}

\section{at $2.5 \mathrm{Bar} \mathrm{H}_{2}$}

Figure 1 shows in-situ SR-PXD data upon heating the $\gamma-\mathrm{Mg}\left(\mathrm{BH}_{4}\right)_{2}$ at 2.5 bar $\mathrm{H}_{2}$ backpressure until the formation of amorphous phase(s) and/or melting at $\sim 285^{\circ} \mathrm{C}$. The sample was ball-milled before the thermal treatment, following the same procedure adopted for the samples with the additives. The RT pattern of $\gamma-\mathrm{Mg}\left(\mathrm{BH}_{4}\right)_{2}$ (Figure 1) has a high background at small $2 \theta$, which can be assigned to amorphous $\mathrm{Mg}\left(\mathrm{BH}_{4}\right)_{2}$ formed upon material storage [44] and milling [25]. In the $150-200{ }^{\circ} \mathrm{C}$ range, pure $\gamma-\mathrm{Mg}\left(\mathrm{BH}_{4}\right)_{2}$ underwent two phase transitions.
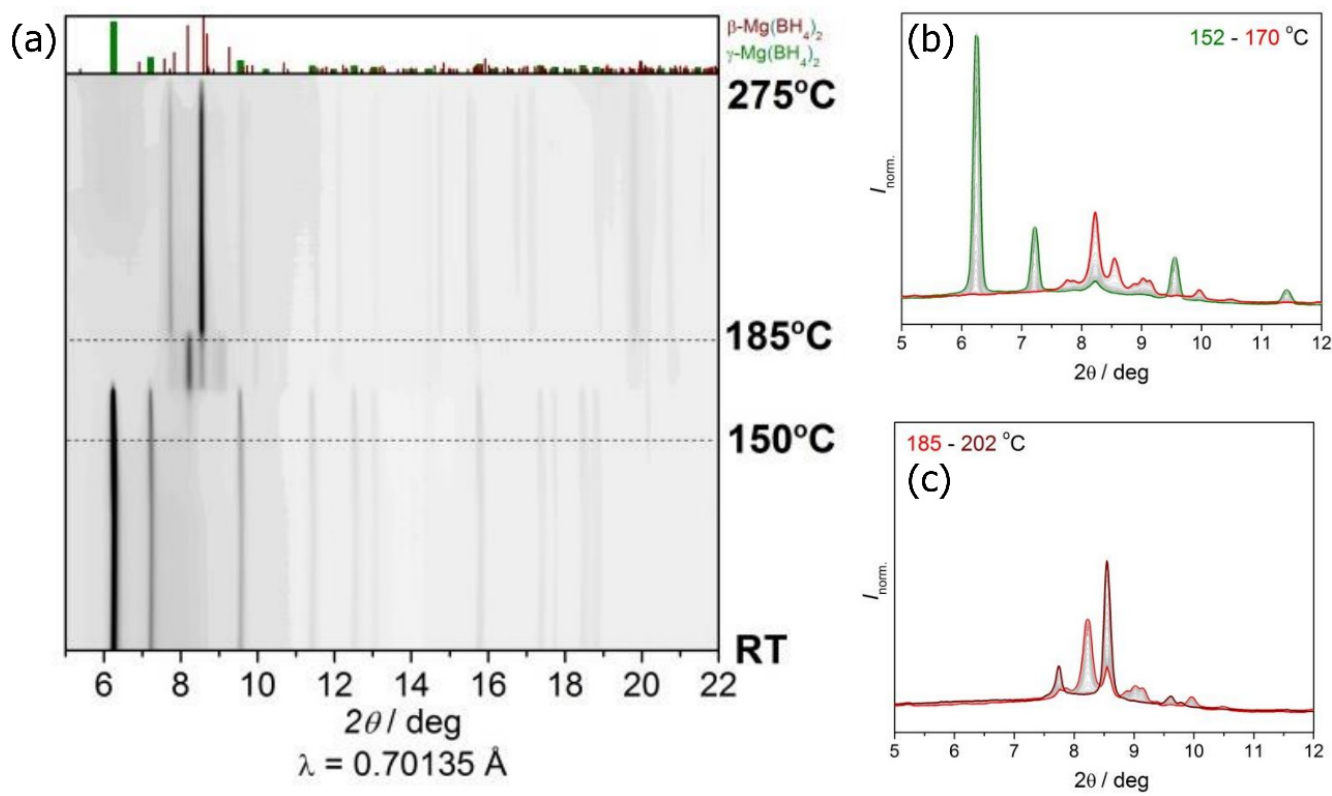

Figure 1. (a) In-situ synchrotron radiation powder X-ray diffraction (SR-PXD) of milled $\gamma-\mathrm{Mg}\left(\mathrm{BH}_{4}\right)_{2}$ obtained by heating the sample from room temperature (RT) to $285^{\circ} \mathrm{C}$ at $5{ }^{\circ} \mathrm{C} / \mathrm{min}$ and 2.5 bar $\mathrm{H}_{2}$. Detailed view: (b) $\gamma \rightarrow \varepsilon$; and (c) $\varepsilon \rightarrow \beta^{\prime}$ phase transitions in $\gamma-\mathrm{Mg}\left(\mathrm{BH}_{4}\right)_{2}$. 
The first phase transition (Figure $1 \mathrm{~b}$ ) to the commonly named $\varepsilon$-phase occurred in the $150-170{ }^{\circ} \mathrm{C}$ temperature range. The PXD pattern of this phase is similar to the one observed earlier [24]. The second phase transition (Figure 1c), to the disordered $\beta-\mathrm{Mg}\left(\mathrm{BH}_{4}\right)_{2}$ or $\beta^{\prime}-\mathrm{Mg}\left(\mathrm{BH}_{4}\right)_{2}$ [45], was observed at $185-202{ }^{\circ} \mathrm{C}$. At about $200{ }^{\circ} \mathrm{C}$ the peak intensities of $\beta^{\prime}-\mathrm{Mg}\left(\mathrm{BH}_{4}\right)_{2}$ started decreasing, together with the simultaneous increase in the amorphous background, which indicated the onset of sample decomposition. At $\sim 285{ }^{\circ} \mathrm{C}$ all crystalline reflections disappeared, in agreement with sample decomposition to the amorphous phases and/or melting [24].
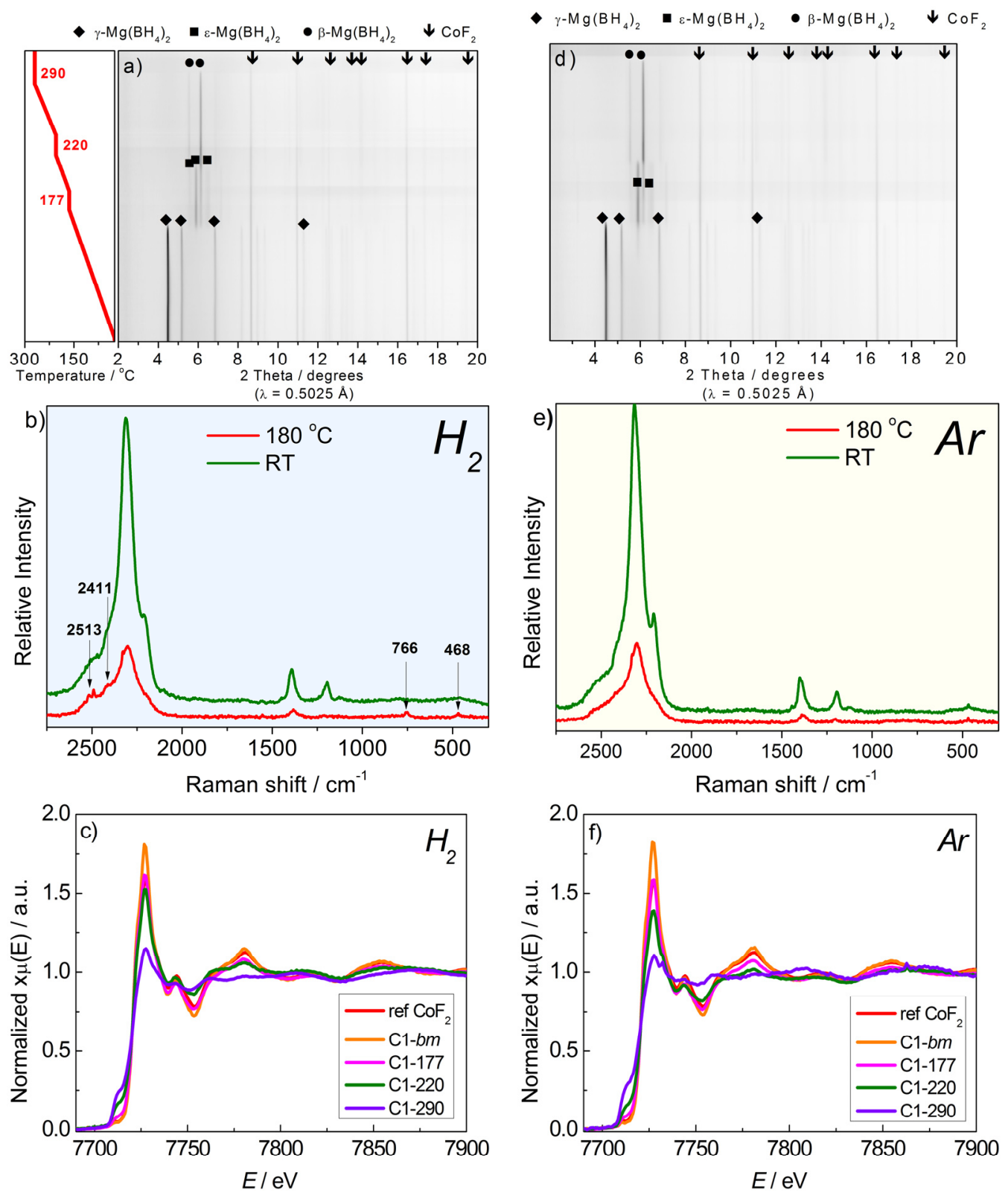

Figure 2. In-situ characterization using (from top to bottom) SR-PXD, Raman and X-ray absorption (XAS) spectroscopies of the thermal decomposition of $\mathrm{Mg}\left(\mathrm{BH}_{4}\right)_{2}+2 \mathrm{~mol} \% \mathrm{CoF}_{2}$ (C1 sample) in the RT-300 ${ }^{\circ} \mathrm{C}$ range in two different annealing environments: (a-c) 2.5 bar $\mathrm{H}_{2}$; and $(\mathbf{d}-\mathbf{f}) 1$ bar Ar. 


\subsection{In-Situ X-ray Diffraction (XRD)/X-ray Absorption Spectroscopy (XAS)/Raman Study of} $\mathrm{Mg}\left(\mathrm{BH}_{4}\right)_{2}+$ Co add Decomposition

\subsection{1. $\mathrm{Mg}\left(\mathrm{BH}_{4}\right)_{2}+\mathrm{CoF}_{2}$}

Figure 2a,d show the series of in-situ SR-PXD data obtained while decomposing the sample

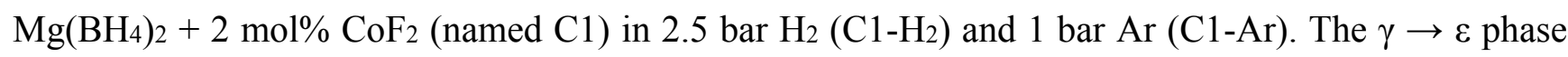
transition in $\mathrm{Ar}$ was observed at a lower temperature than that in $\mathrm{H}_{2}$, in the $\sim 105-160{ }^{\circ} \mathrm{C}$ range vs. $\sim 130-175^{\circ} \mathrm{C}$ in $\mathrm{H}_{2}$. The $\varepsilon \rightarrow \beta^{\prime}$ phase transition occurred at $\sim 175-190{ }^{\circ} \mathrm{C}$ in the $\mathrm{C} 1-\mathrm{H}_{2}$ sample and at $\sim 175-200{ }^{\circ} \mathrm{C}$ in the $\mathrm{C} 1$-Ar sample. Starting from about $220^{\circ} \mathrm{C}$, a change was observed in the amorphous background profile and in the $\beta^{\prime}-\mathrm{Mg}\left(\mathrm{BH}_{4}\right)_{2}$ peaks intensities in the $\mathrm{C} 1-\mathrm{H}_{2}$ sample. Such changes can be related to the decomposition of $\mathrm{Mg}\left(\mathrm{BH}_{4}\right)_{2}$ to amorphous compounds.

Raman spectroscopy can be used to characterize both amorphous and crystalline phases. Raman spectra of the $\mathrm{C} 1$ sample in $\mathrm{H}_{2}$ and Ar obtained at RT before the measurements (Figure 2b,e) in the $2900-600 \mathrm{~cm}^{-1}$ region show peaks due to the vibrations of $\mathrm{BH}_{4}{ }^{-}$molecular ions [46]. The $\mathrm{B}-\mathrm{H}$ stretching modes are centered at $2316 \mathrm{~cm}^{-1}$ (symmetric stretching, $v_{\mathrm{sym}}$ ), and the bending modes are located at ca. 1400 (symmetric bending, $\delta_{\text {sym }}$ ), 1197 and $1120 \mathrm{~cm}^{-1}$ (asymmetric bending, $\delta_{\text {asym}}$ ), respectively [46]. Scattering due to the overtones and combinations of $\mathrm{BH}_{4}{ }^{-}$bending were observed at $\sim 2520$ and $2208 \mathrm{~cm}^{-1}$. The weak broad peaks $>500 \mathrm{~cm}^{-1}$ can be tentatively assigned to the librations of $\left(\mathrm{BH}_{4}\right)^{-}$. The small peak at $468 \mathrm{~cm}^{-1}$ might be due to $\mathrm{CoF}_{2}$ [47]. Heating to $180{ }^{\circ} \mathrm{C}$ caused a gradual decrease of the intensities of $\left(\mathrm{BH}_{4}\right)^{-}$stretching and bending bands, due mainly to thermal effects since no decomposition is expected below $200^{\circ} \mathrm{C}$. No evident new peaks were observed during heating. At $180^{\circ} \mathrm{C}$, new vibrations appeared at 2513, 2411, and $766 \mathrm{~cm}^{-1}$ in samples heated in both $\mathrm{Ar}$ and in $\mathrm{H}_{2}$, although the intensities of these peaks were more pronounced in the spectrum of $\mathrm{C} 1-\mathrm{H}_{2}$. Unfortunately, further decomposition at $>180{ }^{\circ} \mathrm{C}$ could not be followed with Raman measurements, the spectrum being obscured by a strong fluorescence background. This background may be related to the decomposition phase fluorescent with the used laser.

The crystalline additive $\mathrm{CoF}_{2}$ was observed in the SR-PXD patterns after ball-milling and throughout the in-situ measurement until $290{ }^{\circ} \mathrm{C}$, when the $\mathrm{Mg}\left(\mathrm{BH}_{4}\right)_{2}$ either melted or decomposed to amorphous phases. The intensity of $\mathrm{CoF}_{2}$ peaks started to decrease only at $\sim 220{ }^{\circ} \mathrm{C}$, indicating a reaction of the fluoride during heating both in $\mathrm{Ar}$ and in $\mathrm{H}_{2}$.

Co K-edge XAS spectra of sample C1, obtained at the isothermal steps during the in-situ measurement in $\mathrm{H}_{2}$ and $\mathrm{Ar}$ are shown in Figure 2 ( $\mathrm{c}$ and $\mathrm{f}$, respectively). The spectrum obtained at RT (orange curve) is very similar to the reference $\mathrm{CoF}_{2}$, indicating that no chemical reactions occurred during ball-milling. No significant modification of the spectra was observed during heating up to $220{ }^{\circ} \mathrm{C}$. However, the spectra obtained at $290{ }^{\circ} \mathrm{C}$ were considerably different, reflecting changes in the oxidation and coordination state of cobalt atoms. The high intensity of the white line in the spectrum at RT is characteristic for cobalt atoms in high oxidation states $\left(\mathrm{CoF}_{2}, \mathrm{CoF}_{3}\right)$ and its decrease is an indication of reduction of cobalt atoms [26]. The observed modifications in the post-edge region ( $c a$. above $7730 \mathrm{eV}$ ) suggest also changes in the structural environment around Co atoms. The final XAS spectrum was not similar to either $\mathrm{Co}_{2} \mathrm{~B}, \mathrm{Co}$ or $\mathrm{CoF}_{2}$, indicating that the additive had reacted to an intermediate phase or mixture of phases. 
In order to clarify the nature of the intermediate phases, reference spectra of pure $\mathrm{Co}_{2} \mathrm{~B}, \mathrm{Co}_{\text {or }} \mathrm{CoF}_{2}$ were collected. The linear combination fitting (LCF) of the spectra of $\mathrm{C} 1$ decomposed in $\mathrm{H}_{2}$ and in $\mathrm{Ar}$ are reported in Figure 3a-f, respectively, for three temperatures: $177(\mathrm{a}, \mathrm{d}), 220(\mathrm{~b}, \mathrm{e})$ and $290{ }^{\circ} \mathrm{C}(\mathrm{c}, \mathrm{f})$.
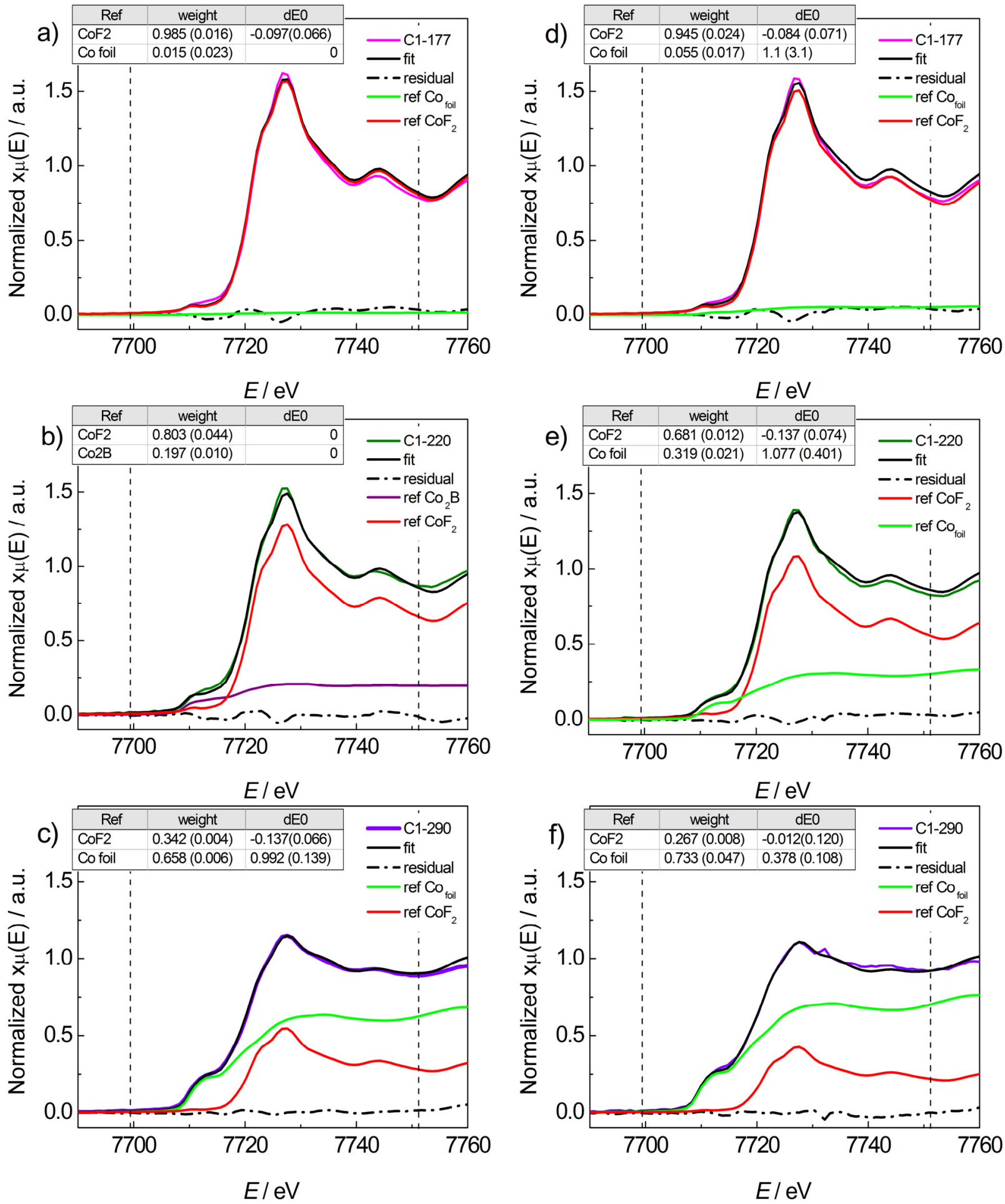

Figure 3. Linear combination fitting (LCF) of $\mathrm{C} 1-\mathrm{H}_{2}(\mathbf{a}-\mathbf{c})$ and $\mathrm{C} 1-\mathrm{Ar}(\mathbf{d}-\mathbf{f})$ XAS spectra recorded (from top to bottom) at $177{ }^{\circ} \mathrm{C}, 220{ }^{\circ} \mathrm{C}$ and $290{ }^{\circ} \mathrm{C}$ using $\mathrm{CoF}_{2}, \mathrm{Co}$, and $\mathrm{Co}_{2} \mathrm{~B}$ as references. All combinations of the three references were used in the fit, with the weight sum set to 1 ; the edge energy parameter, $E_{0}$, was freed and $\Delta E_{0}$ denotes its shift after fitting. The fit range is shown by vertical dashed lines. The errors are indicated in parenthesis. 
LCFs of $\mathrm{C} 1-\mathrm{H}_{2}$ show that the additive was still primarily composed of $\mathrm{CoF}_{2}$ at $177^{\circ} \mathrm{C}$ with a residual part converted in a new phase, which was present in too small quantity to be properly fitted. At $220^{\circ} \mathrm{C}$, the best fit was obtained with the $\mathrm{CoF}_{2}$ and $\mathrm{Co}_{2} \mathrm{~B}$ references, whereas at $290{ }^{\circ} \mathrm{C} \mathrm{CoF}_{2}$ and $\mathrm{Co}$ had to be used. Notably, the amounts of $\mathrm{CoF}_{2}$ regularly decreased in the spectra collected at increasing temperatures. However, the attempts to obtain better fits with consistently $\mathrm{Co} 2 \mathrm{~B}$ or $\mathrm{Co}$ for the $220{ }^{\circ} \mathrm{C}$ and $290{ }^{\circ} \mathrm{C}$ spectra were unsuccessful, resulting in unacceptably large shifts in $E_{0}(>9 \mathrm{eV})$ and visibly bad fits. The poor fit at the two highest temperatures can be an indication of other than the references phase(s). On the basis of the LCF analysis, it can be suggested that at $\sim 200{ }^{\circ} \mathrm{C} \mathrm{CoF}_{2}$ formed borides which were transformed to metallic nano-clusters (giving no diffraction peaks) at higher temperature. The spectrum of $\mathrm{C} 1$-Ar sample (Figure $3 \mathrm{~d}-\mathrm{f}$ ) obtained at $177{ }^{\circ} \mathrm{C}$ was best fitted with $\mathrm{CoF}_{2}$ and Co foil references, although the fit with $\mathrm{CoF}_{2}$ and $\mathrm{Co}_{2} \mathrm{~B}$ (not shown) was only slightly worse. Notable is the large shift in the edge energy, $\Delta \mathrm{E}_{0}$, (both in the fit with $\mathrm{Co}$ foil and $\mathrm{Co}_{2} \mathrm{~B}$ ) and small amount of the new phase. The large $\Delta \mathrm{E}_{0}$ can indicate that the reference set was not strictly adequate to the actual composition of the additive and/or that the amount of the new cobalt phase was too low to obtain meaningful fit. The satisfactory fit with $\mathrm{CoF}_{2}$ and Co references of the $\mathrm{C} 1-\mathrm{Ar}$ spectra obtained at $220^{\circ} \mathrm{C}$ and $290{ }^{\circ} \mathrm{C}$ indicates a gradual transformation of $\mathrm{CoF}_{2}$ to metallic cobalt with increasing temperature.

\subsection{2. $\mathrm{Mg}\left(\mathrm{BH}_{4}\right)_{2}+\mathrm{CoCl}_{2}$}

$\mathrm{Mg}\left(\mathrm{BH}_{4}\right)_{2}+2 \mathrm{~mol} \% \mathrm{CoCl}_{2}$ (named $\mathrm{C} 2$ in the following) was annealed only in Ar. The $\gamma \rightarrow \varepsilon$ and $\varepsilon \rightarrow \beta^{\prime}$ phase transitions in $\mathrm{Mg}\left(\mathrm{BH}_{4}\right)_{2}$ were observed at $\sim 107-150{ }^{\circ} \mathrm{C}$ and $\sim 177-190{ }^{\circ} \mathrm{C}$, respectively (Figure 4a). The onset temperature for the decrease in the intensity of diffraction peaks due to $\beta^{\prime}-\mathrm{Mg}\left(\mathrm{BH}_{4}\right)_{2}$ was $\sim 220{ }^{\circ} \mathrm{C}$. The Raman spectrum of $\mathrm{C} 2$ at $\mathrm{RT}$ was similar to that of samples $\mathrm{C} 1$ (Figure $4 \mathrm{~b}$, green line) but, at about $180{ }^{\circ} \mathrm{C}$, the sample was already fluorescent and all vibrational features were obscured (red curve in Figure 4b). The diffraction peaks of the crystalline $\mathrm{CoCl}_{2}$ additive were observed in the PXD pattern of the sample after milling indicating that the additive had not reacted with $\mathrm{Mg}\left(\mathrm{BH}_{4}\right)_{2}$.

In the in-situ SR-PXD measurements (Figure 4a), the intensities of the peaks for $\mathrm{CoCl}_{2}$ remained unaltered up to $200{ }^{\circ} \mathrm{C}$. At this temperature they started to decrease, and disappeared completely by $290^{\circ} \mathrm{C}$. On the contrary, in-situ XAS spectra (Figure 4c) showed a larger temperature dependence of Co coordination and oxidation state. A strong change in the XAS spectra was observed during the $177^{\circ} \mathrm{C}$ isotherm. In particular, after $5 \mathrm{~min}$ at $177^{\circ} \mathrm{C}$ the spectrum (Figure $4 \mathrm{c}$, brown curve) was very different from the one recorded at RT. It suggests that the local environment around cobalt in the $\mathrm{CoCl}_{2}$ additive was significantly altered already at this temperature. $\mathrm{LCF}$ of the first spectrum in the sequence at $177^{\circ} \mathrm{C}$ (Figure $4 \mathrm{~d}$ ) indicated that $\mathrm{Co}$ was present mostly as $\mathrm{CoCl}_{2}(\sim 88 \%)$. However, the spectrum recorded only after $\sim 5$ min shows that the amount of $\mathrm{CoCl}_{2}$ was reduced by half (Figure $4 \mathrm{e}$ ). A nano-scale dimension of the Co particles could explain the absence of the peaks due to metallic Co in the SR-PXD patterns. The residuals in the fitting of the XAS-data indicate that, as for the C1-Ar and $\mathrm{C} 1-\mathrm{H}_{2}$ sample, a considerable amount of $\mathrm{Co}$ atoms were in the oxidation/coordination states different from those of the references. Further changes were observed in the spectrum obtained at $290^{\circ} \mathrm{C}$. Fitting this spectrum with the available references was unsuccessful, indicating that the Co atoms were mainly bound in unidentified compounds. The XAS spectrum obtained by quenching C2-Ar at RT after the experiment 
(light green curve in Figure 4c) showed further chemical transformations of the Co-additive. Also in this case, LCF did not give any meaningful results with the available references.
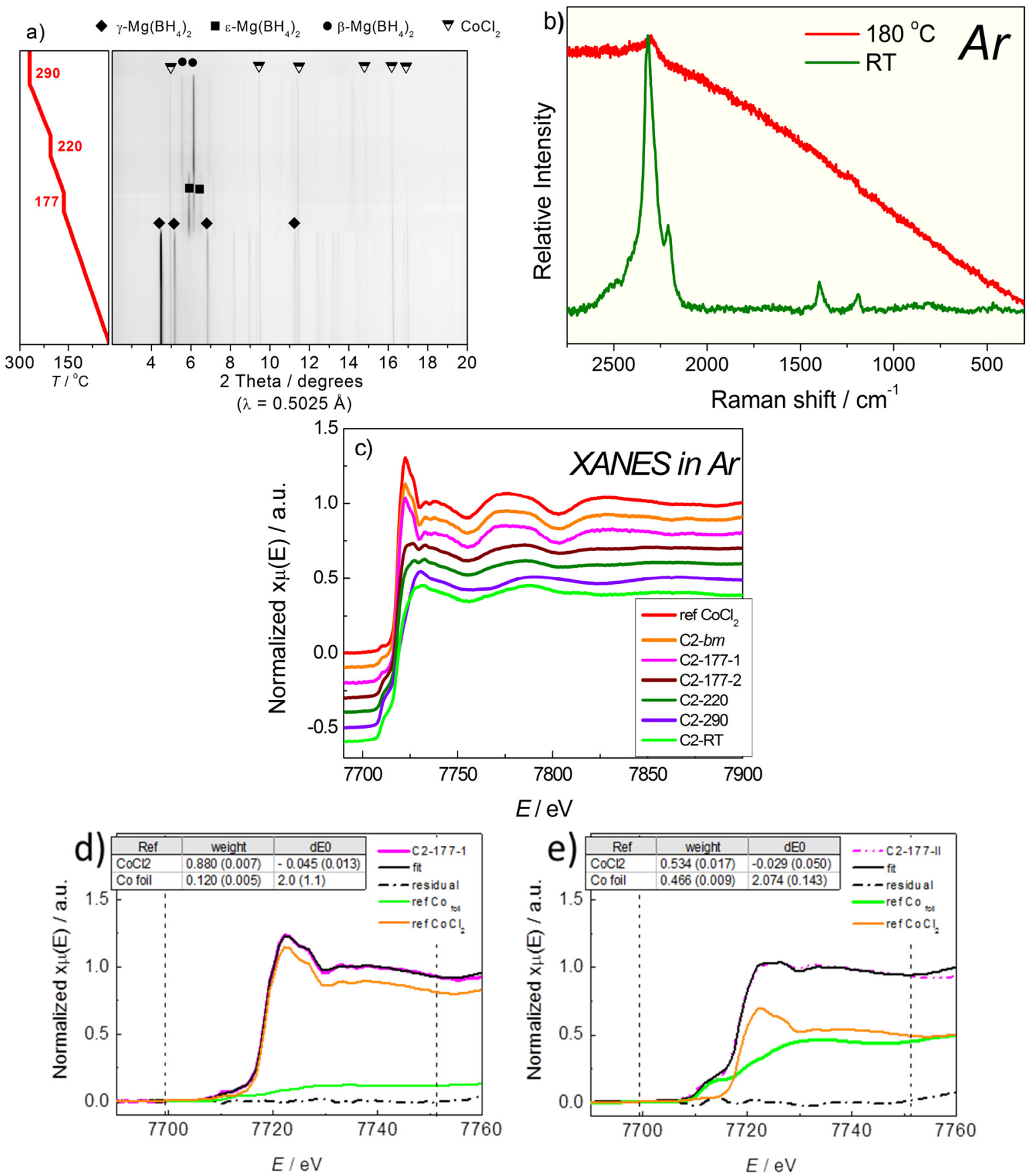

Figure 4. In-situ characterization of the thermal decomposition of $\mathrm{Mg}\left(\mathrm{BH}_{4}\right)_{2}+2 \mathrm{~mol} \%$ $\mathrm{CoCl}_{2}$ in $\mathrm{Ar}$ in the $\mathrm{RT}-290{ }^{\circ} \mathrm{C}$ range. (a) SR-PXD at increasing $T$; (b) Raman spectra at RT (green) and at $180{ }^{\circ} \mathrm{C}$ (red); (c) Co K-edge XAS spectra of $\mathrm{CoCl}_{2}$ reference (at RT) and $\mathrm{C} 2$ recorded at different temperatures and at RT after the measurements (light green). XAS spectra are y-offset for clarity. LCF of $\mathrm{C} 2-\mathrm{Ar}$ with $\mathrm{CoF}_{2}, \mathrm{Co}$, and $\mathrm{Co}_{2} \mathrm{~B}$ references: at $177{ }^{\circ} \mathrm{C}$ (d) and after $5 \mathrm{~min}$ at $177^{\circ} \mathrm{C}(\mathbf{e})$. All combinations of the three references were used in the fit with the weight sum set to 1 ; the $E_{0}$ parameter was freed. The fit range is shown by dashed lines. The errors are indicated in parenthesis. 
The as-milled sample was additionally characterized by TEM (Figure 5). A TEM image (Figure 5a) illustrates variable size of the sample particles ranging from some tens of nanometers to over a hundred nanometers. Figure 5b shows a dark-field scanning (S)TEM image of several particles in the sample, along with the corresponding energy dispersive spectroscopy (EDS) maps. The Mg map identifies the main $\mathrm{Mg} / \mathrm{B}$ phase particles. Figure $5 \mathrm{c}$ shows electron energy loss spectroscopy (EELS) spectra obtained from three different representative positions in the sample. The positions of the B-K, Cl- $\mathrm{L}_{2,3}, \mathrm{C}-\mathrm{K}, \mathrm{O}-\mathrm{K}$ and $\mathrm{Co}-\mathrm{L}_{2,3}$ peaks are indicated. Curve 1 from a discrete particle of the additive phase exhibits strong peaks due to $\mathrm{Cl}$ and $\mathrm{Co}$. Carbon in the spectrum is due to the slight contamination of the sample and the fact that the electron beam was passing through the carbon support film. Curves 2 and 3 were obtained from the positions indicated in the STEM image of an aggregate of particles shown in the dark-field STEM image of Figure $5 \mathrm{~d}$.

Curve 2 is from the main part of the particle. The prominent oxygen peaks indicate some oxidation of the sample which could have happened during transportation and handling. A strong B peak is also present and the EELS map for this element is also shown on the Figure 5d. There is no Mg peak in the energy range of the EELS spectra, but the presence of this element was confirmed by the Mg map of Figure 5b, which includes the aggregate of Figure $5 \mathrm{~d}$.

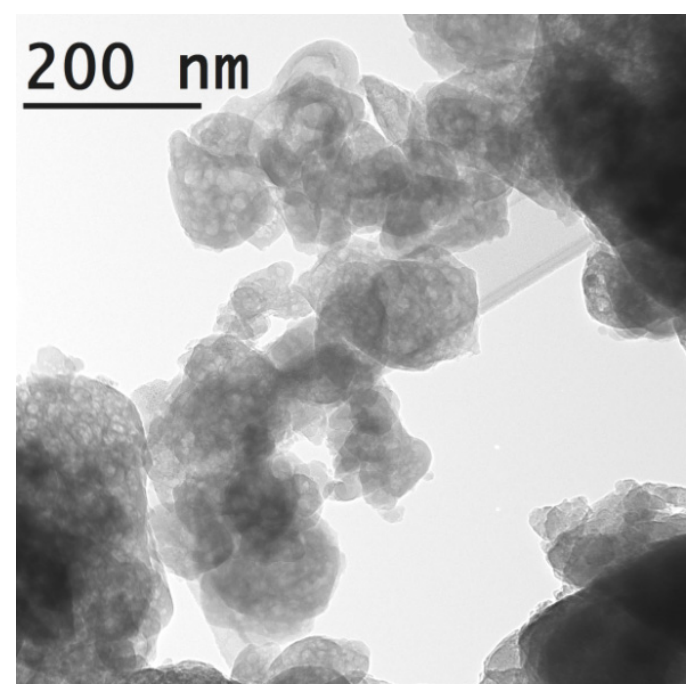

(a)

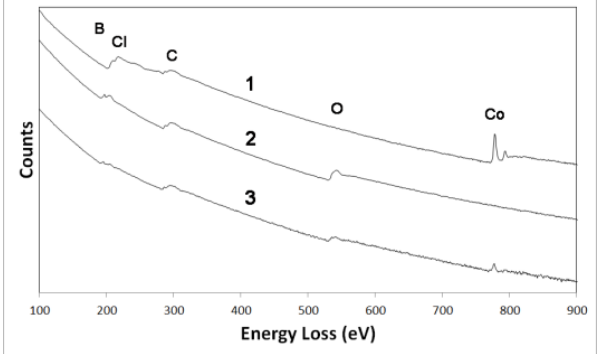

(c)
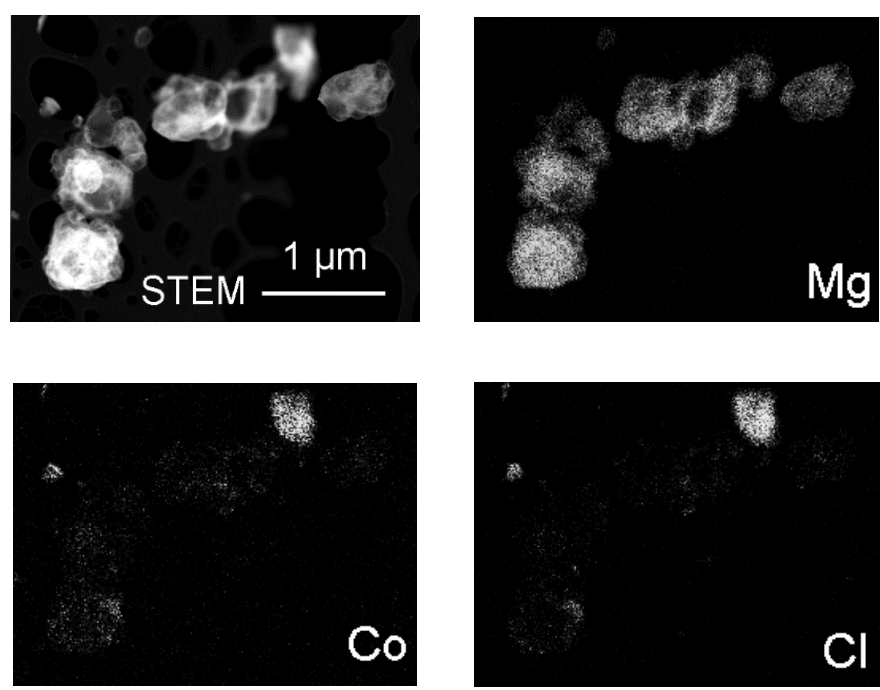

(b)
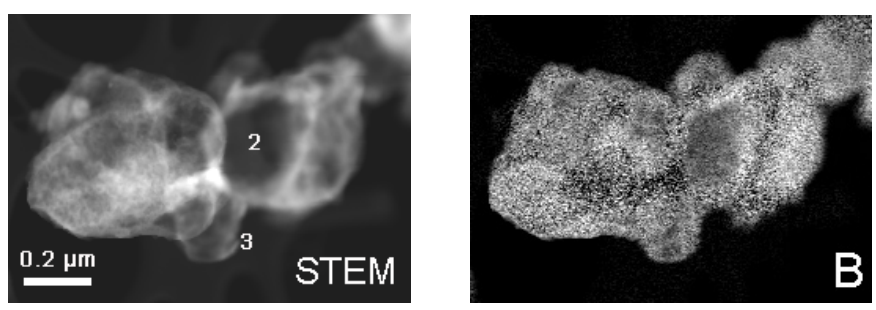

(d)

Figure 5. Transmission electron microscopy (TEM) observations of C2-bm sample. (a) TEM image showing $\mathrm{Mg}\left(\mathrm{BH}_{4}\right)_{2}$ particles dispersed on $\mathrm{C}$ support film; (b) STEM image and EDS maps; (c) EELS spectra from different positions in the specimen; (d) STEM image and Boron EELS map from region included in (b). 
The $\mathrm{Co}$ and $\mathrm{Cl}$ maps indicate similar distributions of these elements confirming that most of the additive remained as $\mathrm{CoCl}_{2}$ phase after milling and confirming the PXD results. However, the maps show also that a small amount of the elements is associated with the $\mathrm{Mg} / \mathrm{B}$ phase, which suggests breaking up of $\mathrm{CoCl}_{2}$ and its incorporation into the borohydride matrix. It should be mentioned that the EDS maps are susceptible to variations in background intensity when the level of elements is low.

Spectrum 3 of Figure $5 \mathrm{c}$ was obtained from a small area at the particle surface. It shows the presence of $\mathrm{Co}$, in addition to $\mathrm{B}$ and $\mathrm{O}$, and relatively smaller amount of $\mathrm{Cl}$, which suggests that a small amount of a chlorine-less phase of cobalt had formed at the particle surfaces during ball milling. In this way, TEM and SR-PXD analyses (Figure 4) show that most of $\mathrm{CoCl}_{2}$ additive did not react with the sample during ball-milling.

A comparison between the XAS spectra of the $\mathrm{C} 1$ and $\mathrm{C} 2$ samples obtained at $290{ }^{\circ} \mathrm{C}$ is shown in Figure 6a. It is clear that the $\mathrm{CoF}_{2}$ and $\mathrm{CoCl}_{2}$ additives did not form identical compounds at this stage (violet and pink curves). In particular, cobalt in $\mathrm{CoF}_{2}$ at $290{ }^{\circ} \mathrm{C}$ both in $\mathrm{H}_{2}$ and $\mathrm{Ar}$ preserves higher oxidation state than the cobalt in $\mathrm{CoCl}_{2}$. This is evident both from the slightly higher edge energy $(7721 \mathrm{eV}$ vs. $7718 \mathrm{eV}$ in $\mathrm{CoF}_{2}$ and $\mathrm{CoCl}_{2}$, respectively) and more intense white line. Meanwhile the XAS spectra of $\mathrm{CoCl}_{2}$ obtained at $290{ }^{\circ} \mathrm{C}$ and at RT after the measurements also show some differences which can probably be explained by temperature-related changes in the cobalt coordination state.
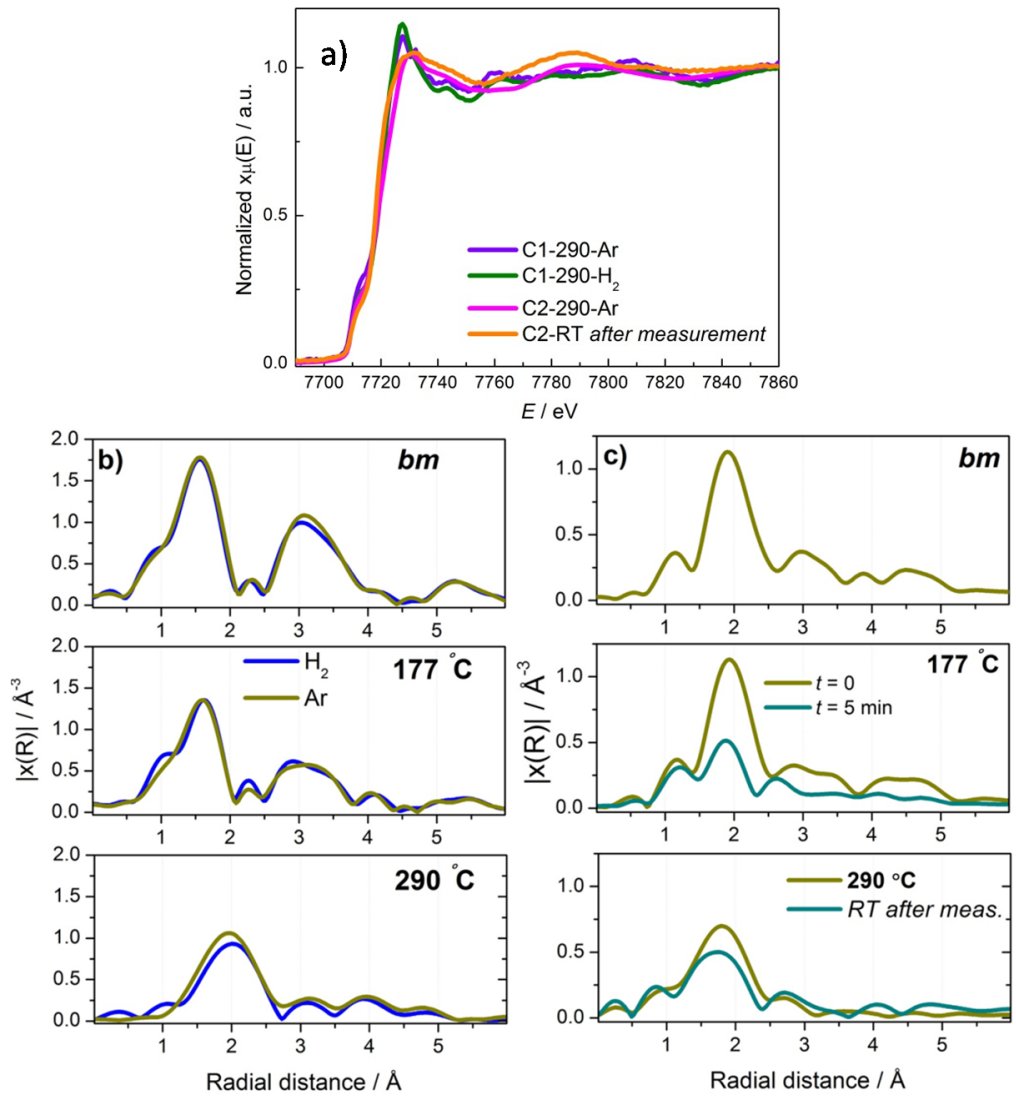

Figure 6. (a) Co K-edge XAS spectra of the $\mathrm{C} 1$ sample at $290^{\circ} \mathrm{C}$ obtained in $\mathrm{Ar}$ (violet line) and $\mathrm{H}_{2}$ (green line) and XAS spectrum of $\mathrm{C} 2$ sample at $290{ }^{\circ} \mathrm{C}$ in $\mathrm{Ar}$ pink curve). The spectrum recorded after quenching $\mathrm{C} 2$ at RT is also reported for comparison (yellow line). Co K-edge $\mathrm{k}^{2}$-weighted FT-transform moduli of the EXAFS signals (phase-uncorrected) at different temperatures of (b) $\mathrm{C} 1-\mathrm{H} 2$ and $\mathrm{C} 1-\mathrm{Ar}$ and (c) $\mathrm{C} 2-\mathrm{Ar}$. 
Fourier transform of the extended X-ray absorption fine structure (FT-EXAFS) spectra are presented in Figure 6b, c for samples $\mathrm{C} 1$ and $\mathrm{C} 2$, respectively. These graphs show the moduli part of the FT of the $\mathrm{k}^{2}$-weighted EXAFS signal. The latter represents the radial distribution function centered on Co atom. The position of each peak in the FT corresponds to an average length (after phase correction, $\Delta \varphi$ ) of a single scattering path or to the convolution of more than one path, whereas the intensity is related to the number of the nearest neighbors and structural disorder in the system.

In the spectrum of $\mathrm{C} 1-\mathrm{bm}\left(\mathrm{CoF}_{2}\right.$ additive, Figure $\left.6 \mathrm{~b}\right)$, the first (and most intense) peak at $1.56 \AA$ corresponds to the backscattering from the six fluorine atoms in the first coordination shell of cobalt [26]. These atoms are located at 2.01 and $2.06 \AA$, thus giving the phase difference, $\Delta \varphi$, of $0.45-0.5 \AA$. This first peak shifts to 1.63 and $1.96 \AA$ upon heating to $177{ }^{\circ} \mathrm{C}$ and $290{ }^{\circ} \mathrm{C}$, respectively (Figure 6b). The reduction in the peak intensity can be explained by structural disorder around cobalt and/or decrease in the coordination number. The peaks at 2.5-4.2 $\AA$ are composed by several contributions from different scatterers with predominant contributions from cobalt atoms at $3.2 \AA$ and $3.7 \AA$ and from $\mathrm{F}$ atoms at 3.6-3.8 $\AA$ [26]. The intensity of these peaks decreased significantly with temperature (Figure 6b) reflecting more disorder in the distant coordination shells. At $220^{\circ} \mathrm{C}$, a new peak at $2.2 \AA$ appeared in the spectra, which shifted to $2.0 \AA$ at $290{ }^{\circ} \mathrm{C}$ and became the only feature in the spectra. These changes in cobalt environment upon heating can be explained by atomic rearrangements around cobalt. Firstly, the Co-F distances increase by $\sim 0.1 \AA$ due to the thermal lattice expansion and a simultaneous decrease in the number of the first shell neighbors. Above $200^{\circ} \mathrm{C}$ new neighboring atoms appeared around cobalt with the new coordination shell formed at $\sim 2.45 \AA(2.0+\Delta \varphi)$. This value is very close to the interatomic distances in cobalt metal $(2.42 \AA)$. Furthermore it can be noted that the EXAFS spectra (Figure $6 \mathrm{~b}$ ) obtained at $290 \AA$ do not exhibit the shoulder at low radial distance which would correspond to the first-shell $B$ neighbors [26]. Thus, it can be suggested that cobalt metal clusters, rather than cobalt boride species, were the predominant phases formed by the $\mathrm{CoF}_{2}$ additive in this study. The changes in cobalt environment observed upon $\mathrm{C} 1$ decomposition in $\mathrm{Ar}$ and $\mathrm{H}_{2}$ were very similar, suggesting a small effect of the atmosphere on the chemical transformations in the additive in the present temperature range. Therefore, the slight difference in the $\gamma-\varepsilon$ phase-transition and decomposition temperature of $\mathrm{Mg}\left(\mathrm{BH}_{4}\right)_{2}$, observed in the in-situ SR-PXD (Section 2.2.1) should be attributed to the different atmosphere.

The analysis of the EXAFS spectra conducted for the $\mathrm{C} 2$ sample $\left(\mathrm{CoCl}_{2}\right.$ additive) is shown in Figure 6c. Also in this case the radial distribution function for the as milled sample indicates that the additive was essentially unreacted during the milling. In fact, the most intense peaks at $1.9 \AA$ and $3.0 \AA$ are due to the scattering from $\mathrm{Cl}$ and $\mathrm{Co}$ neighbors located in $\mathrm{CoCl}_{2}$ at 2.5 and $3.6 \AA$, respectively $(\Delta \varphi=0.6 \AA)$ [26]. Up to $177^{\circ} \mathrm{C}$ (Figure 6c), the FT-EXAFS spectra indicates the presence of only one cobalt species, $\mathrm{CoCl}_{2}$. In the spectra collected after $5 \mathrm{~min}$ at $177^{\circ} \mathrm{C}$, a significant change in the local cobalt environment is evident (Figure $6 \mathrm{c}, 177^{\circ} \mathrm{C}$ cyan curve). A strong reduction in the intensity indicates also a highly disordered coordination environment which was preserved upon heating up to $290{ }^{\circ} \mathrm{C}$ and after cooling the sample down to room temperature. In the new cobalt phase the nearest neighbors were located at the distances 2.3-2.4 $\AA$, if the $\Delta \varphi$ obtained from fitting the $\mathrm{CoCl}_{2}$ reference is used. 


\subsection{Discussion}

It has been repeatedly shown that TM-additives, particularly halides, react with the host complex hydride matrix [26,34,42,43]. Even the borides lose long-range order, although preserving the local environment around the metal [26,42]. Therefore, these types of compounds cannot be called catalysts in the classical meaning. Our in-situ study demonstrates that this is also the case for Co-based additives, although some differences can be noticed between $\mathrm{CoF}_{2}$ and $\mathrm{CoCl}_{2} . \mathrm{CoCl}_{2}$ already reacted with $\mathrm{Mg}\left(\mathrm{BH}_{4}\right)_{2}$ at $177^{\circ} \mathrm{C}$, whereas $\mathrm{CoF}_{2}$ was slowly reduced upon heating above this temperature. At $290{ }^{\circ} \mathrm{C}$ both the additives produce highly disordered phases that, however, differ slightly from each other. The EXAFS extraction allowed some information about the cobalt environment in these compounds to be obtained, but their precise nature remains somewhat unclear. In particular, $\mathrm{CoF}_{2}$ forms the species with the first coordination shell at $\sim 2.45 \AA$ whereas for $\mathrm{CoCl}_{2}$ a 2.3-2.4 $\AA$ distance was suggested for the first neighbors. Linear combination fits of the Co K-edge XANES spectra indicate that cobalt metal rather than cobalt boride is formed upon reduction, with the concomitant presence of other, unidentified, phases. In our previous ex-situ study [26], we have found that cobalt additives transform into boride-like species upon cycling with $\mathrm{Mg}\left(\mathrm{BH}_{4}\right)_{2}$. Nevertheless, in that study the ex-situ XAS measurements were performed at least one month after cycling. It may indicate that borides could be formed upon further cycling in $\mathrm{H}_{2}$ and/or ageing of the samples. The in-situ XAS spectra have shown also a gradual change in the cobalt environment in the additives which rules out the low-temperature formation and decomposition of cobalt borohydride. TEM observations suggest that some of the Co was incorporated into the hydride surfaces.

Table 1 summarizes the phase-transitions and decomposition temperatures of the samples, as observed by in-situ SR-PXD in this study. It is notable that the $\gamma \rightarrow \varepsilon$ phase transition occurred about $45{ }^{\circ} \mathrm{C}$ lower in the samples with $\mathrm{CoF}_{2}$ and $\mathrm{CoCl}_{2}$ decomposed in $\mathrm{Ar}$ than in pure milled $\mathrm{Mg}\left(\mathrm{BH}_{4}\right)_{2}$. In the $\mathrm{C} 1-\mathrm{H}_{2}$ sample this temperature was lowered by only $20^{\circ} \mathrm{C}$. A destabilization of the $\gamma$ phase (and then a decrease in the temperature of $\gamma \rightarrow \varepsilon$ transition) can be explained on the basis of the effect of the additive on the metastable nature of the porous $\gamma-\mathrm{Mg}\left(\mathrm{BH}_{4}\right)_{2}$. A smaller effect was observed also in the onset temperature of the $\varepsilon \rightarrow \beta^{\prime}$ phase transition, which was lowered by $10{ }^{\circ} \mathrm{C}$ in all cases. The $T_{\mathrm{dec}}$, which was defined as the onset of the decrease in the diffraction peaks intensities of the $\beta^{\prime}$ phase and increase in the amorphous halo intensity, was similar for all the samples. $\mathrm{C} 1-\mathrm{H}_{2}$ appeared to be stabilized by the $\mathrm{CoF}_{2}$ additive. It is noteworthy as only in this case the LCF of the XANES spectra did not evidence the partial transformation of the Co-additive in Co metal particles for $T$ lower than $220^{\circ} \mathrm{C}$.

Table 1. Summary of phase transition and decomposition temperatures of the $\operatorname{Mg}\left(\mathrm{BH}_{4}\right)_{2}$ samples obtained in this study.

\begin{tabular}{|c|c|c|c|c|}
\hline Event & $\begin{array}{l}\mathrm{Mg}\left(\mathrm{BH}_{4}\right)_{2} \\
\text { Milled-H2 }\end{array}$ & $\begin{array}{c}\mathrm{C} 1\left(\mathrm{Mg}\left(\mathrm{BH}_{4}\right)_{2}+0.2 \mathrm{~mol} \%\right. \\
\left.\mathrm{CoF}_{2}\right) / \mathrm{H}_{2} \\
\end{array}$ & $\begin{array}{c}\mathrm{C} 1\left(\mathrm{Mg}\left(\mathrm{BH}_{4}\right)_{2}+0.2 \mathrm{~mol} \%\right. \\
\left.\mathrm{CoF}_{2}\right) / \mathrm{Ar} \\
\end{array}$ & $\begin{array}{c}\mathrm{C} 2\left(\mathrm{Mg}\left(\mathrm{BH}_{4}\right)_{2}+0.2 \mathrm{~mol} \%\right. \\
\left.\mathrm{CoCl}_{2}\right) / \mathrm{Ar} \\
\end{array}$ \\
\hline $\begin{array}{c}\gamma \rightarrow \varepsilon \text { phase } \\
\text { transition }\end{array}$ & $150-170{ }^{\circ} \mathrm{C}$ & $130-175^{\circ} \mathrm{C}$ & $105-160^{\circ} \mathrm{C}$ & $107-150^{\circ} \mathrm{C}$ \\
\hline $\begin{array}{c}\varepsilon \rightarrow \beta^{\prime} \text { phase } \\
\text { transition }\end{array}$ & $185-202{ }^{\circ} \mathrm{C}$ & $175-190^{\circ} \mathrm{C}$ & $175-200^{\circ} \mathrm{C}$ & $175-190^{\circ} \mathrm{C}$ \\
\hline Decomposition & $>200^{\circ} \mathrm{C}$ & $>220^{\circ} \mathrm{C}$ & $>200^{\circ} \mathrm{C}$ & $>200^{\circ} \mathrm{C}$ \\
\hline
\end{tabular}


Raman spectra of C2-Ar have shown that the sample became strongly fluorescent at $180{ }^{\circ} \mathrm{C}$, whereas $\mathrm{C} 1-\mathrm{H}_{2}$ and C1-Ar still had well defined Raman scattering. This could indicate that the $\mathrm{CoCl}_{2}$ lowers $T_{\text {dec }}$ of $\mathrm{Mg}\left(\mathrm{BH}_{4}\right)_{2}$. At the same time, since the PXD data have shown similar decomposition temperatures for both $\mathrm{C} 1$ and $\mathrm{C} 2$, the fluorescence could also originate from the reacted cobalt additive. Raman spectra of the $\mathrm{C} 1-\mathrm{H}_{2}$ gave also the peaks at 2513,2411, and $766 \mathrm{~cm}^{-1}$, belonging to an unidentified boron hydride phase. The values at $2513 \mathrm{~cm}^{-1}$ and $2411 \mathrm{~cm}^{-1}$ are similar to the $\mathrm{BH}$ stretching in higher boron hydrides whereas the peak at $766 \mathrm{~cm}^{-1}$ is in the range of the B-B stretching of these compounds. It is notable that no peaks were observed in the $1800-2200 \mathrm{~cm}^{-1}$ region where the $\mathrm{B}-\mathrm{H}-\mathrm{B}$ stretching of bridged hydrogen atoms should appear [48].

The question on how Co-additives affect the decomposition process of $\mathrm{Mg}\left(\mathrm{BH}_{4}\right)_{2}$ is intriguing, especially taking into account the literature results on $\mathrm{Ni}$ and Co-additives effect on the decomposition of borohydrides and related compounds. It should be noted though that the most prominent results, such as dramatic decrease in $T_{\mathrm{dec}}$, was observed for the samples where additives were combined with other destabilization approaches, for example, dispersion in the highly porous media $[36,43]$ or mixing with electron-rich compounds [41]. The effects of pure additives on pure borohydrides could thus be attributed simply to chemical reactions between the two and the ball-milling process usually used to prepare the composites. The large effect of the ball milling alone on the partial decomposition and rehydrogenation of pure $\mathrm{Mg}\left(\mathrm{BH}_{4}\right)_{2}$ was recently demonstrated [26].

\section{Experimental Section}

All procedures were carried out in a glove box under a continuously purified Ar atmosphere $\left(\mathrm{O}_{2}\right.$, $\left.\mathrm{H}_{2} \mathrm{O}<1 \mathrm{ppm}\right)$ if not stated otherwise. Commercial $\gamma-\mathrm{Mg}\left(\mathrm{BH}_{4}\right)_{2}(95 \%$, Sigma-Aldrich, St. Louis, MO, USA) was used. XRD analysis of this sample showed that the crystalline fraction of this batch was constituted by $\gamma-\mathrm{Mg}\left(\mathrm{BH}_{4}\right)_{2}$. $\mathrm{CoCl}_{2}$ (99.999\%), and $\mathrm{CoF}_{2}$ were purchased from Sigma-Aldrich. The starting powder mixtures consisted of $\mathrm{Mg}\left(\mathrm{BH}_{4}\right)_{2}$ and $2 \mathrm{~mol} \%$ of an additive (Coadd). The milling was carried out in stainless steel vials and balls with a 40:1 ball-to-powder weight ratio. $\mathrm{Pure} \mathrm{Mg}\left(\mathrm{BH}_{4}\right)_{2}$ and the additives were milled for $1 \mathrm{~h}$ at $280 \mathrm{rpm}$ under $1 \mathrm{bar}$ Ar pressure.

In-situ SR-PXD of the ball-milled $\gamma-\mathrm{Mg}\left(\mathrm{BH}_{4}\right)_{2}$ decomposition was performed at the Swiss-Norwegian Beam Line (station BM01A) at the European Synchrotron Radiation Facility (ESRF) in Grenoble, France. The X-ray wavelength $\lambda=0.70153 \AA$ was used. The combined in-situ SR-PXD, XAS, and Raman spectroscopies data were collected at the station BM01B at ESRF [49]. For the measurements in Ar, the samples were placed in borosilicate capillaries (1.0 $\mathrm{mm}$ in diameter) and sealed in the glove-box with the air-tight glue. For the measurements in $\mathrm{H}_{2}$, the capillaries were attached to a sample holder enabling connection to a gas line. Before the measurements in $\mathrm{H}_{2}$, the samples were degassed in vacuum at RT, and 2.5 bar $\mathrm{H}_{2}$ pressure was set in the capillaries. The capillaries were heated by a calibrated hot blower. Temperature calibration was carried out with In and Sn standards (experimental melting points were obtained at the nominal temperatures 145 (In) (theoretical. $156.61{ }^{\circ} \mathrm{C}$ ) and $219(\mathrm{Sn})$, theoretical $231.9^{\circ} \mathrm{C}$ ). The samples were heated up to $290^{\circ} \mathrm{C}$ with a $5^{\circ} \mathrm{C} / \mathrm{min}$ heating rate with two isothermal pauses at $177^{\circ} \mathrm{C}$ and $220^{\circ} \mathrm{C}$ of $60 \mathrm{~min}$. After reaching $290{ }^{\circ} \mathrm{C}$, the samples were kept at that temperature for several hours. SR-PXD data were collected every 0.5 min during the heating ramps and every 4 min at 
the isothermal steps. XAS scans were obtained during the isothermal steps every 5 min. Raman spectra were collected during the experiments until the samples became fluorescent at about $180{ }^{\circ} \mathrm{C}$.

SR-PXD data were collected with a wavelength of $0.5025 \AA$. 2D images were obtained with an exposure time of $30 \mathrm{~s}$ using an image plate detector. A number of dark-current images (17-90 for different ramps and isothermal steps) were obtained before the sample scans, averaged, and subsequently subtracted from the sample images.

In-situ XAS data were collected in the XANES and EXAFS regions in the energy range 7.6-8.6 keV comprising Co K-edge at $7.7089 \mathrm{keV}$ in transmission mode using a double crystal Si (111) monochromator. The spectrum of the Co foil (hcp) was used as a reference for data calibration and alignment. The spectra of the reference powders- $\mathrm{CoF}_{2}, \mathrm{CoF}_{3}, \mathrm{CoCl}_{2}$, used in the preparation of the composites, and additionally Co powder (99.5\%, Alfa Aesar, Ward Hill, MA, USA), Co2B (American Elements, Los Angeles, CA, USA), and $\mathrm{CoO}(>99.99 \%$, Aldrich) were measured diluted with boron nitride to $2 \mathrm{~mol} \%$ of Coadd. XAS data analysis was carried out with DEMETER software pack (ATHENA and ARTEMIS, B. Ravel and M. Newville, Brookhaven National Laboratory, Upton NY, USA) [50]. The spectra were pre-processed in ATHENA (background subtracted, aligned, the step scans were averaged and used for final plots and fitting). Liner combination analyses (fits, LCF) in the range from $-30 \mathrm{eV}$ to $+20 \mathrm{eV}$ were performed with the ATHENA software. Calculation of the theoretical scattering paths in the EXAFS region and fitting were performed with the FEFF6 code [51] using ARTEMIS. Due to the low concentration of the additive and the small sample quantities required by the capillaries in the experimental set-up, the energy step was low and the spectra obtained were rather noisy, especially in the EXAFS region. Therefore, several consequent spectra, obtained at the higher temperatures were merged in order to increase the signal to noise ratio.

Raman spectra were collected on an RA 100 Raman analyzer (Renishaw, New Mills, UK) using a $532 \mathrm{~nm}$ (green) excitation wavelength in backscattering mode with exposure times of $200 \mathrm{~s}$ and step of $1.2 \mathrm{~cm}^{-1}$ over a $3200-200 \mathrm{~cm}^{-1}$ range.

TEM was performed in the NORTEM TEM Gemini Centre, Norwegian University of Science and Technology (NTNU), Norway, using an ARM200F instrument (JEOL, Tokyo, Japan) operating at $200 \mathrm{kV}$. A JEOL Centurio detector was used for EDS analysis and a Gatan and EELS using a Gatan Quantum imaging filter. As-milled sample was studied. Sample preparation was performed in a glove box. A small quantity of the powder was crushed in a mortar and dispersed onto a standard holey carbon film on a $\mathrm{Cu}$ support grid. The sample was rather stable under the electron beam.

\section{Conclusions}

The in-situ study combining X-ray diffraction and absorption, and Raman spectroscopy allowed us to follow several aspects of the decomposition of $\mathrm{Mg}\left(\mathrm{BH}_{4}\right)_{2}-\mathrm{Co}_{\text {add }}$ system simultaneously, i.e., changes in the crystalline and amorphous $\mathrm{Mg}\left(\mathrm{BH}_{4}\right)_{2}$ matrix and in the cobalt-based additives. This approach can provide valuable knowledge on the decomposition process of complex (molecular) hydrides and effect of the metal-based additives on this process. It allowed us to follow the reaction during the thermal treatment, pointing out that the cobalt was reduced by $\mathrm{Mg}\left(\mathrm{BH}_{4}\right)_{2} \cdot \mathrm{CoF}_{2}$ was found to be more stable at a higher temperature than $\mathrm{CoCl}_{2}$. In-situ XAS measurements suggested that Co-additives form metal clusters rather than $\mathrm{CoB}_{\mathrm{x}}$ species upon reduction. In case of $\mathrm{CoCl}_{2}$ additive, TEM observations suggest 
that small amount of the Co was incorporated into the hydride surfaces already after ball-milling although the main additive phase remained as $\mathrm{CoCl}_{2}$. The identification of the amorphous fraction of the $\mathrm{Mg}\left(\mathrm{BH}_{4}\right)_{2}$ decomposition products by means of Raman scattering was hindered by fluorescence with the $532 \mathrm{~nm}$ laser, and the data obtained at higher temperature were not very informative. However, we were still able to observe that one of the decomposition products had the vibrational modes at 2513, 2411, and $766 \mathrm{~cm}^{-1}$, belonging to an unidentified boron hydride phase. These vibrations are very similar to the ones measured by means of infrared spectroscopy in a previous study on $\mathrm{Mg}\left(\mathrm{BH}_{4}\right)_{2}$ decomposition [52].

\section{Acknowledgments}

This work was financed by the European Fuel Cells and Hydrogen Joint Undertaking under collaborative project "BOR4STORE" (Grant Agreement No. 303428). Partial financial support from SYNKNØYT program in the Research Council of Norway is greatly acknowledged. TEM analysis was supported by the NORTEM (Grant 197405) within the program INFRASTRUCTURE of the Research Council of Norway (RCN). NORTEM was co-funded by the RCN and the project partners NTNU, UiO and SINTEF. We thank the beamline scientists Paula Abdala, Herman Emerich, and Wouter van Beek at the BM01B SNBL for their help with the measurements.

\section{Author Contributions}

Stefano Deledda, Bjørn C. Hauback, Jiri Muller, Ivan Saldan, and Olena Zavorotynska have initiated the research and planned the experiments. Olena Zavorotynska, Ivan Saldan, Jenny G. Vitillo, and Matylda N. Guzik have carried out most of the experimental work and analyzed the results. Olena Zavorotynska wrote the manuscript with substantial revisions from Jenny G. Vitillo and Stefano Deledda; John C. Walmsley carried out TEM measurements and data analysis. All the authors significantly contributed to the editing and improvement of the manuscript.

\section{Conflicts of Interest}

The authors declare no conflict of interest.

\section{References}

1. George, L.; Saxena, S.K. Structural stability of metal hydrides, alanates and borohydrides of alkali and alkali-earth elements: A review. Int. J. Hydrog. Energy 2010, 35, 5454-5470.

2. Li, H.-W.; Yan, Y.; Orimo, S.; Zuttel, A.; Jensen, C.M. Recent Progress in Metal Borohydrides for Hydrogen Storage. Energies 2011, 4, 185-214.

3. Hummelshoj, J.S.; Landis, D.D.; Voss, J.; Jiang, T.; Tekin, A.; Bork, N.; Dulak, M.; Mortensen, J.J.; Adamska, L.; Andersin, J.; et al. Density functional theory based screening of ternary alkali-transition metal borohydrides: A computational material design project. J. Chem. Phys. 2009, 131, doi:10.1063/1.3148892.

4. Besora, M.; Lledos, A. Coordination modes and hydride exchange dynamics in transition metal tetrahydroborate complexes. In Contemporary Metal Boron Chemistry I: Borylenes, Boryls, Borane; Marder, T.B., Lin, Z., Eds.; Springer: Berlin, Germany, 2008; pp. 149-202. 
5. Marks, T.J.; Kolb, J.R. Covalent transition metal, lanthanide, and actinide tetrahydroborate complexes. Chem. Rev. 1977, 77, 263-293.

6. Callini, E.; Borgschulte, A.; Ramirez-Cuesta, A.J.; Zuettela, A. Diborane release and structure distortion in borohydrides. Dalton Trans. 2013, 42, 719-725.

7. Chong, M.; Callini, E.; Borgschulte, A.; Zuettel, A.; Jensen, C.M. Dehydrogenation studies of the bimetallic borohydrides. RSC Adv. 2014, 4, 63933-63940.

8. Albanese, E.; Civalleri, B.; Casassa, S.; Baricco, M. Investigation on the Decomposition Enthalpy of Novel Mixed $\mathrm{Mg}_{(1-x)} \mathrm{Zn}_{x}\left(\mathrm{BH}_{4}\right)_{2}$ Borohydrides by Means of Periodic DFT Calculations. J. Phys. Chem. C 2014, 118, 23468-23475.

9. Schouwink, P.; Ley, M.B.; Tissot, A.; Hagemann, H.; Jensen, T.R. Smrčok, L.; Černý, R. Structure and properties of complex hydride perovskite materials. Nat. Commun. 2014, 5, doi:10.1038/ncomms6706.

10. Wang, J.; Li, H.W.; Chen, P. Amides and borohydrides for high capacity solid-state hydrogen storage-Materials design and kinetics improvement. MRS Bull. 2013, 38, 480-487.

11. Li, H.-W.; Kikuchi, K.; Sato, T.; Nakamori, Y.; Ohba, N.; Aoki, M.; Miwa, K.; Towata, S.; Orimo, S. Synthesis and Hydrogen Storage Properties of a Single-Phase Magnesium Borohydride $\mathrm{Mg}\left(\mathrm{BH}_{4}\right)_{2}$. Mater. Trans. 2008, 49, 2224-2228.

12. Matsurtaga, T.; Buchter, F.; Miwa, K.; Towata, S.; Orimo, S.; Zuttel, A. Magnesium borohydride: A new hydrogen storage material. Renew. Energy 2008, 33, 193-196.

13. Filinchuk, Y.; Richter, B.; Jensen, T.R.; Dmitriev, V.; Chernyshov, D.; Hagemann, H. Porous and Dense Magnesium Borohydride Frameworks: Synthesis, Stability, and Reversible Absorption of Guest Species. Angew. Chem. Int. Ed. 2011, 50, 11162-11166.

14. Roennebro, E. Development of group II borohydrides as hydrogen storage materials. Curr. Opin. Solid State Mater. Sci. 2011, 15, 44-51.

15. Ozolins, V.; Akbarzadeh, A.R.; Gunaydin, H.; Michel, K.; Wolverton, C.; Majzoub, E.H. First-principles computational discovery of materials for hydrogen storage. J. Phys. Conf. Ser. 2009, 180, doi:10.1088/1742-6596/180/1/012076.

16. Ozolins, V.; Majzoub, E.H.; Wolverton, C. First-principles prediction of a ground state crystal structure of magnesium borohydride. Phys. Rev. Lett. 2008, 100, doi:10.1103/PhysRevLett.100.135501.

17. Van Setten, M.J.; de Wijs, G.A.; Fichtner, M.; Brocks, G. A density functional study of $\alpha-\mathrm{Mg}\left(\mathrm{BH}_{4}\right)_{2}$. Chem. Mater. 2008, 20, 4952-4956.

18. Pinatel, E.R.; Albanese, E.; Civalleri, B.; Baricco, M. Thermodynamic modelling of $\mathrm{Mg}\left(\mathrm{BH}_{4}\right)_{2}$. J. Alloys Compd. 2015, 645, S64-S68

19. Riktor, M.D.; Sorby, M.H.; Chlopek, K.; Fichtner, M.; Buchter, F.; Zuttel, A.; Hauback, B.C. In situ synchrotron diffraction studies of phase transitions and thermal decomposition of $\mathrm{Mg}\left(\mathrm{BH}_{4}\right)_{2}$ and $\mathrm{Ca}\left(\mathrm{BH}_{4}\right)_{2}$. J. Mater. Chem. 2007, 17, 4939-4942.

20. Hanada, N.; Chlopek, K.; Frommen, C.; Lohstroh, W.; Fichtner, M. Thermal decomposition of $\mathrm{Mg}\left(\mathrm{BH}_{4}\right)_{2}$ under He flow and $\mathrm{H}_{2}$ pressure. J. Mater. Chem. 2008, 18, 2611-2614.

21. Soloveichik, G.L.; Gao, Y.; Rijssenbeek, J.; Andrus, M.; Kniajanski, S.; Bowman, R.C., Jr.; Hwan, S.-J.; Zhao, J.-C. Magnesium borohydride as a hydrogen storage material: Properties and dehydrogenation pathway of unsolvated $\mathrm{Mg}\left(\mathrm{BH}_{4}\right)_{2}$. Int. J. Hydrog. Energy 2009, 34, 916-928. 
22. Yan, Y.; Li, H.-W.; Maekawa, H.; Aoki, M.; Noritake, T.; Matsumoto, M.; Miwa, K.; Towata, S.; Orimo, S. Formation Process of $\left[\mathrm{B}_{12} \mathrm{H}_{12}\right]^{2-}$ from $\left[\mathrm{BH}_{4}\right]^{-}$during the Dehydrogenation Reaction of $\mathrm{Mg}\left(\mathrm{BH}_{4}\right)_{2}$. Mater. Trans. 2011, 52, 1443-1446.

23. Yang, J.; Zhang, X.; Zheng, J.; Song, P.; Li, X. Decomposition pathway of $\mathrm{Mg}\left(\mathrm{BH}_{4}\right)_{2}$ under pressure: Metastable phases and thermodynamic parameters. Scr. Mater. 2011, 64, 225-228.

24. Paskevicius, M.; Pitt, M.P.; Webb, C.J.; Sheppard, D.A.; Filso, U.; Gray, E.M.; Buckley, C.E. In-Situ X-ray Diffraction Study of $\gamma-\mathrm{Mg}\left(\mathrm{BH}_{4}\right)_{2}$ Decomposition. J Phys. Chem. C 2012, 116, 15231-15240.

25. Guo, S.; Chan, H.Y.L.; Reed, D.; Book, D. Investigation of dehydrogenation processes in disordered $\gamma-\mathrm{Mg}\left(\mathrm{BH}_{4}\right)_{2}$. J. Alloys Compd. 2013, 580, S296-S300.

26. Zavorotynska, O.; Saldan, I.; Hino, S.; Humphries, T.D.; Deledda, S.; Hauback, B.C. Hydrogen cycling in $\gamma-\mathrm{Mg}\left(\mathrm{BH}_{4}\right)_{2}$ with cobalt-based additives. J. Mater. Chem. A 2015, 3, 6592-6602.

27. Chong, M.; Karkamkar, A.; Autrey, T.; Orimo, S.-I.; Jalisatgi, S.; Jensen, C.M. Reversible dehydrogenation of magnesium borohydride to magnesium triborane in the solid state under moderate conditions. Chem. Commun. 2011, 47, 1330-1332.

28. Zavorotynska, O.; Deledda, S.; Li, G.; Matsuo, M.; Orimo, S.-I.; Hauback, B.C. Isotopic Exchange in Porous and Dense Magnesium Borohydride. Angew. Chem. Int. Ed. 2015, doi:10.1002/ anie.201502699.

29. Brown, W.G.; Kaplan, L.; Wilzbach, K.E. The exchange of hydrogen gas with lithium and sodium borohydrides. J. Am. Chem. Soc. 1952, 74, 1343-1344.

30. Gremaud, R.; Lodziana, Z.; Hug, P.; Willenberg, B.; Racu, A.-M.; Schoenes, J.; Ramirez-Cuesta, A.J.; Clark, S.J.; Refson, K.; Züttel, A.; et al. Evidence for hydrogen transport in deuterated $\mathrm{LiBH}_{4}$ from low-temperature Raman-scattering measurements and first-principle calculations. Phys. Rev. B 2009, 80, 1-4.

31. Mesmer, R.E.; Jolly, W.L. The Exchange of Deuterium with Solid Potassium Hydroborate. J. Am. Chem. Soc. 1962, 84, 2039-2042.

32. Van Setten, M.J.; Lohstroh, W.; Fichtner, M. A new phase in the decomposition of $\operatorname{Mg}\left(\mathrm{BH}_{4}\right)_{2}$ : First-principles simulated annealing. J. Mater. Chem. 2009, 19, 7081-7087.

33. Bogdanovic, B.; Schwickardi, M. Ti-doped alkali metal aluminium hydrides as potential novel reversible hydrogen storage materials. J. Alloys Compd. 1997, 253-254, 1-9.

34. Mao, J.F.; Yu, X.B.; Guo, Z.P.; Liu, H.K.; Wu, Z.; Ni, J. Enhanced hydrogen storage performances of $\mathrm{NaBH}_{4}-\mathrm{MgH}_{2}$ system. J. Alloys Compd. 2009, 479, 619-623.

35. Zhang, B.J.; Liu, B.H. Hydrogen desorption from $\mathrm{LiBH}_{4}$ destabilized by chlorides of transition metal Fe, Co, and Ni. Int. J. Hydrog. Energy 2010, 35, 7288-7294.

36. Wahab, M.A.; Jia, Y.; Yang, D.; Zhao, H.; Yao, X. Enhanced hydrogen desorption from $\operatorname{Mg}\left(\mathrm{BH}_{4}\right)_{2}$ by combining nanoconfinement and a Ni catalyst. J. Mater. Chem. A 2013, 1, 3471-3478.

37. Xu, J.; Qi, Z.; Cao, J.; Meng, R.; Gu, X.; Wang, W.; Chen, Z. Reversible hydrogen desorption from $\mathrm{LiBH}_{4}$ catalyzed by graphene supported Pt nanoparticles. Dalton Trans. 2013, 42, 12926-12933.

38. Humphries, T.D.; Kalantzopoulos, G.N.; Llamas-Jansa, I.; Olsen, J.E.; Hauback, B.C. Reversible Hydrogenation Studies of $\mathrm{NaBH}_{4}$ Milled with Ni-Containing Additives. J. Phys. Chem. C 2013, $117,6060-6065$. 
39. Au, Y.S.; Yan, Y.; de Jong, K.P.; Remhof, A.; de Jongh, P.E. Pore Confined Synthesis of Magnesium Boron Hydride Nanoparticles. J. Phys. Chem. C 2014, 118, 20832-20839.

40. Zhang, Z.G.; Wang, H.; Liu, J.W.; Zhu, M. Thermal decomposition behaviors of magnesium borohydride doped with metal fluoride additives. Thermochim. Acta 2013, 560, 82-88.

41. Zhang, Y.; Liu, Y.; Pang, Y.; Gao, M.; Pan, H. Role of $\mathrm{Co}_{3} \mathrm{O}_{4}$ in improving the hydrogen storage properties of a $\mathrm{LiBH}_{4}-2 \mathrm{LiNH}_{2}$ composite. J. Mater. Chem. A 2014, 2, 11155-11161.

42. Saldan, I.; Hino, S.; Humphries, T.D.; Zavorotynska, O.; Chong, M.; Jensen, C.M.; Deledda, S.; Hauback, B.C. Structural changes observed during the reversible hydrogenation of $\mathrm{Mg}\left(\mathrm{BH}_{4}\right)_{2}$ with Ni-based additives. J. Phys. Chem. C 2014, 118, 23376-23384.

43. Ngene, P.; Verkuijlen, M.H.W.; Zheng, Q.; Kragten, J.; van Bentum, P.J.M.; Bitter, J.H.; de Jongh, P.E. The role of $\mathrm{Ni}$ in increasing the reversibility of the hydrogen release from nanoconfined $\mathrm{LiBH}_{4}$. Faraday Discuss. 2011, 151, 47-58.

44. Ban, V.; Soloninin, A.V.; Skripov, A.V.; Hadermann, J.; Abakumov, A.; Filinchuk, Y. Pressure-Collapsed Amorphous $\mathrm{Mg}\left(\mathrm{BH}_{4}\right)_{2}$ : An Ultradense Complex Hydride Showing a Reversible Transition to the Porous Framework. J. Phys. Chem. C 2014, 118, 23402-23408.

45. David, W.I.F.; Callear, S.K.; Jones, M.O.; Aeberhard, P.C.; Culligan, S.D.; Pohl, A.H.; Johnson, S.R.; Ryan, K.R.; Parker, J.E.; Edwards, P.P.; et al. The structure, thermal properties and phase transformations of the cubic polymorph of magnesium tetrahydroborate. Phys. Chem. Chem. Phys. 2012, 14, 11800-11807.

46. Giannasi, A.; Colognesi, D.; Ulivi, L.; Zoppi, M.; Ramirez-Cuesta, A.J.; Bardaji, E.G.; Roehm, E.; Fichtner, M. High Resolution Raman and Neutron Investigation of $\mathrm{Mg}\left(\mathrm{BH}_{4}\right)_{2}$ in an Extensive Temperature Range. J. Phys. Chem. A 2010, 114, 2788-2793.

47. Shimanouchi, T.; Nakagawa, I. Infrared spectroscopic study on the co-ordination bond-I: Infrared spectra of cobalt hexammine, pentammine and trans-tetraammine complexes. Spectrochim. Acta 1962, 18, 89-100.

48. Tomkinson, J.; Ludman, C.J.; Waddington, T.C. IR Raman and Inelastic Neutron-Scattering Spectra of Cesium Octahydroborate, $\mathrm{C}_{\mathrm{S}} \mathrm{B}_{3} \mathrm{H}_{8}$. Spectrochim. Acta Part A Mol. Biomol. Spectrosc. 1979, 35, 117-122.

49. Newton, M.A.; van Beek, W. Combining synchrotron-based X-ray techniques with vibrational spectroscopies for the in situ study of heterogeneous catalysts: A view from a bridge. Chem. Soc. Rev. 2010, 39, 4845-4863.

50. Ravel, B.; Newville, M. ATHENA, ARTEMIS, HEPHAESTUS: Data analysis for X-ray absorption spectroscopy using IFEFFIT. J. Synchrotron Radiat. 2005, 12, 537-541.

51. Rehr, J.J.; Albers, R.C. Theoretical approaches to x-ray absorption fine structure. Rev. Mod. Phys. 2000, 72, 621-654.

52. Vitillo, J.G.; Bordiga, S.; Baricco, M. Spectroscopic and structural characterization of thermal decomposition of $\gamma-\mathrm{Mg}\left(\mathrm{BH}_{4}\right)_{2}$ : Dynamic vacuum vs. $\mathrm{H}_{2}$ atmosphere. J. Phys. Chem. C 2015, in press.

(C) 2015 by the authors; licensee MDPI, Basel, Switzerland. This article is an open access article distributed under the terms and conditions of the Creative Commons Attribution license (http://creativecommons.org/licenses/by/4.0/). 